Suppes, T., BnLdessnean, R. J., Faedon, G. L., et al (1991) Piak of recurrence following discontinuation of ththtum treatment in btpolar disorder. Archtues of General Psychiatry, 48, 1082-1088.

TYreser, S. P., Shopsan, B. \& Aronson, M. (1983) Dangers of reducing lithium. Brttsh Joumal of Psychtatry. 148. 427.
D. H. Myers, Consultant Psychifatrist, Shelton Hospital Shrewsbury SY3 8DN; and M. J. Hallworth, Consultant Blochemist, Royal Shrewsbury Hospital, Shrewsbury SY3 8DN

-Correspondence

\title{
An investigation into lithium monitoring
}

\author{
D. H. Myers and M. J. Hallworth
}

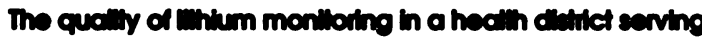
a popilation of 460000 wos studied over a patod of a yeer. The following indences of poor monilioting were

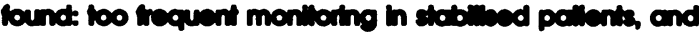
kellurs to take action when milum vatues kell below $0.3 \mathrm{mmol} / \mathrm{h}$ or roes cbove $1.0 \mathrm{mmol}$. Ways of improving tho standend of moniloting are condidered.

Precautionary measures can be overdone. The British National Formulary (BNF, British Medical Association \& Royal Pharmaceutical Society of Great Britain. 1995) used to advocate routine monthly monitoring of serum lithium. Schou (1988) suggested that routine monitoring is not worth the cost or effort, a refreshing statement on a topic that needed simplification. The issue turns on whether patients, once stabilised, will remain so. Kehoe \& Mander (1992) found that in 18 of 458 patients there was a gradual increase in serum lithium concentration during the course of a year, sufficient to require dose reduction. Such patients were found to have an unexplained $18 \%$ lower creatinine clearance rate than controls (Kehoe, 1994). This is important because 95\% of ingested lithium is excreted renally (Dyson et al, 1987). Until more is known, it is reasonable to follow the current BNF (1995) recommendation of monitoring at 3-monthly intervals or even 6monthly in young and middle-aged patients who are reliable (Ferrier et al, 1995).

However, there is no disagreement that it is essential to estimate serum lithium at the start of treatment, during intercurrent lliness, and if there is the slightest suspicion of intoxication.

\section{The study}

The Biochemistry Laboratory of the Shropshire District Health Authority, one of the 23 district laboratories in the West Midlands Region, keeps a record of all lithium estimates, together with information culled from the request forms. The quality of monitoring was assessed from these data which covered the interval from lst January 1991 to 31st October 1992. All estimates were included in the study.

The time elapsing between two consecuttve estimates is referred to as the 'interval' of the second estimate.

The estimates were considered as four classes, the boundaries being dertved from the BNF(1995):

(a) 0-0.3 mmol/1: probably too low to be effective;

(b) 0.4-1.0 mmol/l: the recommended therapeutic range;

(c) 1.1-1.4 mmol/1: effecttve but high, and usually incurring unnecessarly severe side-effects; and

(d) 1.5 and above, 'toxdc'.

If any lithium value lay outside the BNF range (0.4-1.0 mmol/1), or if any interval was stx months or more, or less than one month, further information was sought from case notes and from family doctor records.

\section{Findings}

\section{General}

The mean value of the 2697 lithium estimates was $0.63 \mathrm{mmol} / 1 ; 213$ (7.9\%) fell below the BNF range, 64 (2.4\%) fell in the range 1.1-1.4 mmol/1. and $14(0.5 \%)$ were in the toxic range. 


\section{Frequency of estimation}

For this analysis, only intervals of 28 days or more were considered, shorter intervals not being regarded as routine. The median of these intervals was 62 days, and the mean within-patient interval was 70.2 days (s.d.=29.3 days).

\section{Poor monitoring}

In 47 patients, no action was taken when serum lithium values fell to $0.3 \mathrm{mmol} / 1$ or below. Several patients were treated for many months with what were probably sub-therapeutic doses, one being maintained at $0.1 \mathrm{mmol} / 1$ for 172 days and another between 0.1 and $0.3 / 1$ for 366 days.

In 24 patients, no action was taken when lithium values rose above the BNF range. The worst instances were: values all above $1.0 \mathrm{mmol} /$ 1 for 368 days with a final value of $1.4 \mathrm{mmol} / \mathrm{l}$, itself not prompting action for a further 58 days; 72 days between one estimate of $1.2 \mathrm{mmol} / 1$ and the next: 90 days between an estimate of $1.4 \mathrm{mmol} / \mathrm{l}$ and the next (at $1.5 \mathrm{mmol} / \mathrm{l}) ; 28$ days between an estimate of $1.3 \mathrm{mmol} / 1$ and the next (at $1.8 \mathrm{mmol} / \mathrm{l}$ ).

Finally, one 84-year-old patient had a serum value of $2.1 \mathrm{mmol} / 1$ as a result of a diuretic. Warnings in values of 1.4 and $1.2 \mathrm{mmol} / 1 \mathrm{18}$ and 15 days earlier had gone unheeded.

Too frequent monitoring is illustrated by a patient who had 21 estimates in 616 days despite all being in the therapeutic range and including $a$ run of eight successive estimates at $0.5 \mathrm{mmol} / 1$ at $\mathbf{2 8}$ day intervals.

\section{Incidental findings}

One patient developed neurotoxicity at therapeutic lithium levels because of the co-prescription of verapamil.

\section{Comment}

The mean within-patient interval length of 70.3 days, less than the BNF recommendation, indicates that some patients stabllised on lithium are being monitored more often than is necessary.

Another statistic suggesting a lack of rationale in choosing the monitoring interval for stabilised patients is the large within-patient standard deviation of interval at 29.3 days. A large between-patient variation in interval could be justified on the grounds that some patients might require more frequent monitoring than others: those maintained at the upper end of the BNF range, or predisposed to renal disease because of diabetes mellitus, hypertension or the insidious development of prostatic hypertrophy. There is, however, only one rationale for such a large within-patient variation. This is an early recommendation that, once stabilised, the monitoring interval should be progresstvely lengthened (Schou, 1986). This effect was found to account for only $3.6 \%$ of the within-patient variance and adjusting for it reduced the standard deviation by only half a day to 28.8 days. There remained, therefore, an appreciable within-patient variation in interval length even after this initiation effect is allowed for.

In contrast to this over-scrupulous monitoring of stabilised patients, there were lapses: failing to take precautions when prescribing diuretics, and failing to take action when lithium levels rose above $1.0 \mathrm{mmol} / 1$. risking unnecessary sideeffects, or fell below $0.4 \mathrm{mmol} / 1$, risking relapse. The notes of those patients maintained outside the BNF range stated no reasons for doing so.

How might lithium monitoring be improved? Education is vitally important (see previous paper). Since consistent procedure minimises error, there is a strong case for adopting a common regimen and preparation within a District or Trust. If a psychiatrist wishes to treat any individual patient otherwise, then it seems reasonable that he or she should undertake the monitoring.

Finally, lithium monitoring should itself be monitored. In particular, only high standard long-term monitoring will identify those patients whose lithium values gradually increase, and thus lead to a greater understanding of the extent and nature of this phenomenon.

\section{References}

Brmish Medical Assoclation and Royal Pharmaceutical SOCIETY OF GREAT BRTAN (1995) Brttish National Formulary. Number 29. Bath: Bath Press.

Dyson, E. H., SnuPSON, D. Prescort, L. F., et al (1987) Selfpolsoning and therapeutic intoxdcation with Hthium. Human Taxicology, 6, 325-329.

Ferrier, I. N.. TYrer, S. P. \& Beu, A. J. (1995) Lthium therapy. Aduances in Psychiatric Treatment, 1, 102-110.

KEHOE, R. F. (1994) A cross-sectional study of glomerular function in 740 unselected lithium patients. Acta Psychiatrica Scandinavica, 89, 68-71.

- \& MANDER A. J. (1992) Lthium treatment: prescribing and monitoring habits in hospital and general practice. British Medical Joumal, sos, 552-554.

SCHOU, M. (1986) Lthium treatment: a refiresher course. Brttish Joumal of Psychiatry. 149, 541.

- (1988) Serum lithium monitoring of prophylactic treatment. Clinical Pharmacoktnetics, 5, 283-286.

D. H. Myers, Consultant Psychiatrist, Shelton Hospital, Shrewsbury, SY3 8DN; and M. J. Hallworth, Consultant Biochemist, Royal Shrewsbury Hospttal, Shrewsbury SY3 8DN

*Correspondence 